\title{
Erratum to: Games in Operations Management
}

\author{
Jens O. Riis ${ }^{1}$, Riitta Smeds ${ }^{2}$, and Rik Van Landeghem ${ }^{3}$ \\ 1 Aalborg University, Denmark \\ 2 Helsinki University of Technology, Finland \\ ${ }^{3}$ Ghent University, Belgium
}

\section{Erratum to: \\ J.O. Riis et al. (Eds.) \\ Games in Operations Management DOI: $10.1007 / 978-0-387-35506-1$}

The book was inadvertently published with an incorrect name of the copyright holder. The name of the copyright holder for this book is: (c) IFIP International Federation for Information Processing. The book has been updated with the changes. 